\title{
Special features of elimination of phosphorus compounds in aeration tanks
}

\author{
Nina Zaletova*
}

Moscow State University of Civil Engineering, 26, Yaroslavskoye shosse, Moscow, Russia, 129337

\begin{abstract}
In the sewage treatment plants, phosphorus compounds presented constantly, due to the sources of their appearance. In urban wastewater, phosphorus stays in various compounds - dissolved, insoluble, organic, mineral, simple and complex forms. Only phosphates and total phosphorus are monitored in wastewater chemicals laboratories. The data on phosphorus compounds containing in the wastewater of a number of cities is analyzed in the study. The impact of the biological wastewater treatment process on the efficiency of phosphorus removal was assessed. The research was carried out on an experimental technological installation. It is shown that in the original wastewater not only the concentration of total phosphorus and phosphates is constantly varying, but also their ratio. In the process of biological treatment, a number of complex biochemical and physical-chemical processes are parallel: assimilation, hydrolysis, and adsorption. The effectiveness of these processes is influenced by the magnitude of the initial concentration of total phosphorus and the amount of active dose of sludge. It has been recognized that the increased efficiency of the removal of total phosphorus has an effect on both the increase in the active dose of sludge and the size of the initial concentration of total phosphorus. However, the residual concentration of total phosphorus is affected by its original content, while the initial content of the total phosphorus is affected insignificantly.
\end{abstract}

\section{Introduction}

The removal of phosphorus is one of the up-to-date tasks of wastewater treatment. Wastewater brings various compounds of phosphorus into water objects. These are orthophosphates (phosphates), polyphosphates - linear polymers of orthophosphoric acid, which are the part of many detergents of the mixture with synthetic surface-active substances, organic phosphates - complex esters of orthophosphoric acid, phosphates in suspended substances. The total phosphorus determines the total number of phosphorus compounds.

In incoming to treatment plants wastewater, concentrations of various forms of phosphorus are not constant $[1,2]$. Concentrations of total phosphorus $\left(\mathrm{P}_{\text {tot }}\right)$ and phosphates in wastewater constantly changes. At the same time, changes in the intake of phosphates and changes in concentrations of total phosphorus fluctuate in some range which is typical for particular object. The nature of fluctuations in different phosphorus compounds is unpredictable and variations in their concentration are not correlated with each other [3].

*Corresponding author: naz1604@yandex.ru 
Fig. 1 provides an example showing the actual content of total phosphorus and phosphates in the samples of incoming wastewater on waste water treatment plant with a capacity of $20,000 \mathrm{~m}^{3} /$ day during the year [4].

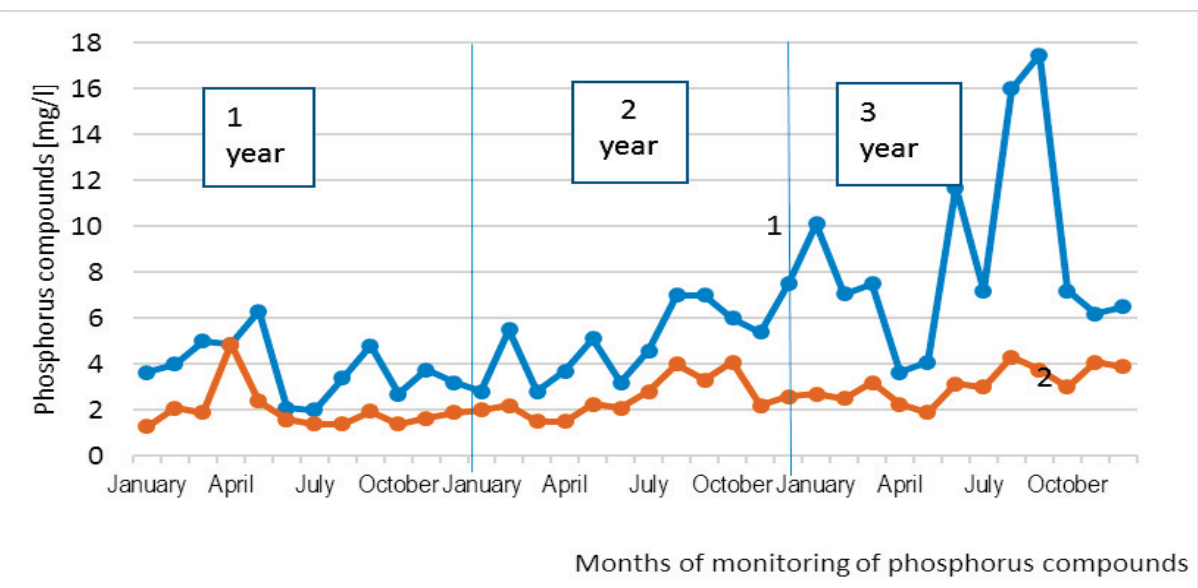

Fig. 1. Average monthly phosphorus compounds in the real urban wastewater: 1 - total phosphorus, 2 - phosphates.

The data characterize the pattern of constant variations in concentrations of phosphate and total phosphorus, and the changes in their values in incoming wastewater.

The most common scheme of wastewater treatment includes the stages of mechanical and biological treatment. Phosphates pass through the stage of mechanical treatment almost in transit. At the same time, the concentration of total phosphorus changes slightly.

The concentration of total phosphorus decreases only by $5-7 \%$ due to the sorption processes realized in the primary tank. All major modifications of phosphorus compounds are carried out in aeration tanks [5-6]. In the process of traditional biological treatment, there is a whole chain of physical, chemical and biological transformations takes place. Schematically, the basic processes for removing phosphorus compounds are given on Fig. 2 .

Phosphates, present in the original wastewater, are partially assimilated by active sludge. Part of the total phosphorus, which is an organic and complex form of phosphorus, is involved in two processes: sorption, consumption and hydrolysis with the formation of phosphates. The part of complex phosphates, which does not react, and organic forms of phosphorus remain in biologically cleansed wastewater [7-9].

Due to hydrolysis of complex forms of phosphorus concentration of phosphates in aeration tank increases. Depending on the ratios of different forms of phosphorus in the wastewater, coming to the treatment, and with the accepted technological parameters of the biological process in the purified water may be not only the reduction of phosphates because of their assimilation, but even their growth.

The content of phosphorus in biologically treated wastewater decreases due to the sorption of phosphorus compounds, hydrolysis of complex and organic phosphates, and the consumption of phosphates by active sludge [10]. 


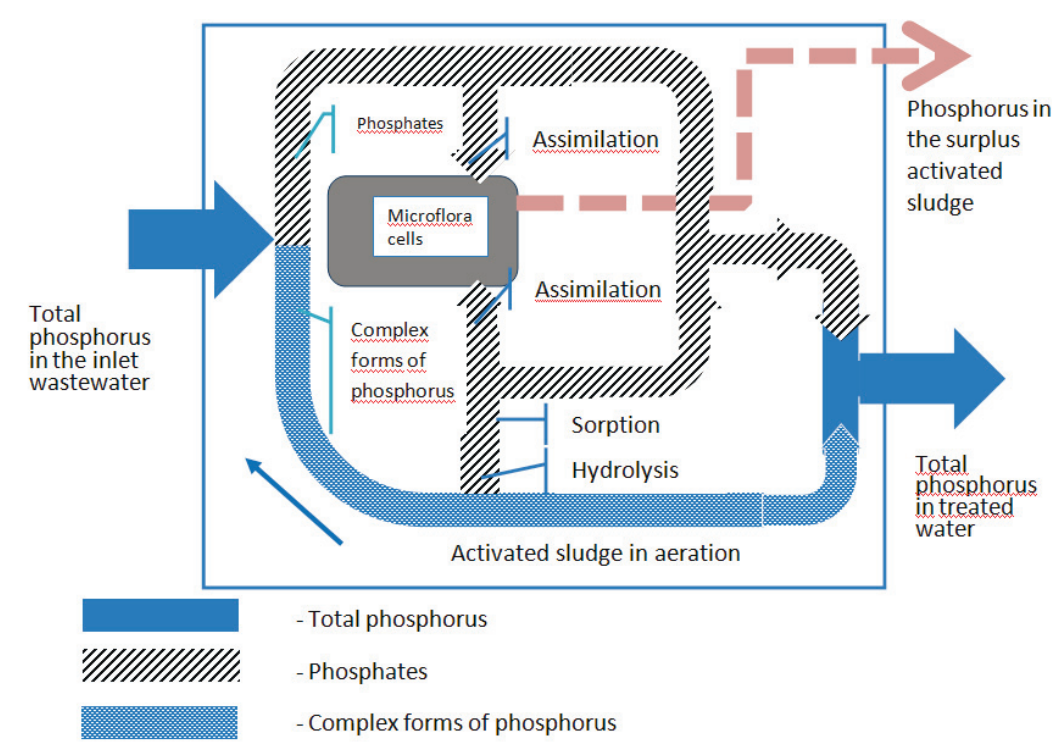

Fig. 2. Scheme of transformation of phosphorus forms in aeration tanks.

\section{Materials and methods}

The researches were carried out on laboratory installation of traditional biological treatment, working on real urban wastewater. The laboratory system included an aeration tank and a secondary settling tank. Installation performance was $40 \mathrm{~L} \mathrm{day}^{-1}$. The installation worked under various technological parameters: the doses of sludge varied within 2 to 6 $\mathrm{g} / \mathrm{L}$. Concentration of total phosphorus in the original water (water from primary sedimentation tank) ranged from 10 to $23 \mathrm{mg} / \mathrm{L}$. In addition, the effectiveness of phosphate removal at treatment plants in some other cities was assessed. Then the results were summarized.

\section{Results}

The results of studies are given on Fig. 3 and in the Table. As shown, the efficiency of the removal of total phosphorus is influenced by two factors: the value of the initial concentration of total phosphorus and the amount of the active dose sludge in the aeration tank.

Table. Effect of the original content of the total phosphorus and activedose of sludge in the aeration tank on the efficiency of the removal of total phosphorus.

\begin{tabular}{|c|c|c|c|}
\hline \multirow{2}{*}{$\begin{array}{c}\text { Initial } \mathbf{P}_{\text {tot }} \\
\text { concentration } \\
{[\mathbf{m g} / \mathbf{L}]}\end{array}$} & \multicolumn{3}{|c|}{ Efficiency of total phosphorus removal [\%] } \\
\cline { 2 - 4 } & MLSS=2 g/L & MLSS = 4 g/L & MLSS = 6 g/L \\
\hline 10,5 & 15 & 19,2 & 38,0 \\
\hline 15,0 & 22,7 & 33,4 & 45,7 \\
\hline 19,0 & 33,0 & 47,4 & 55,6 \\
\hline 23,0 & 45,7 & 61,8 & 74,0 \\
\hline
\end{tabular}

The higher the concentration of total phosphorus is, the higher the effectiveness of its removal is observed. This dependence is seen in the regimes with different doses of active 
sludge. For example, according to the data, with a content of $10.5 \mathrm{mg} / \mathrm{L}$ total phosphorus in incoming wastewater and a working dose of active sludge $2 \mathrm{~g} / \mathrm{L}$, the removal efficiency is $15 \%$, while the flow of wastewater with a concentration of $23 \mathrm{mg} / \mathrm{L}$, the efficiency of removal is already $45,7 \%$. Similar dependence is observed when working with doses $4 \mathrm{~g} / \mathrm{L}$ as well as $6 \mathrm{~g} / \mathrm{L}$. A significant influence on the effectiveness of the removal of total phosphorus has the actual dose of active sludge. For wastewater with a concentration of $\mathrm{P}_{\text {tot }}$ $15 \mathrm{mg} / \mathrm{L}$ at an operational dose of sludge $2 \mathrm{~g} / \mathrm{L}$, the efficiency of removal of total phosphorus is $22.7 \%$, and when dealing with a dose of $6 \mathrm{~g} / \mathrm{L}$, the efficiency of the removal of total phosphorus increases up to $45,7 \%$.

To assess the work of the sludge mixture, the most significant residual content of $\mathrm{P}_{\text {tot }}$ in the treated water is analyzed. Fig. 3 demonstrates the dependence of residual concentrations of $\mathrm{P}_{\text {tot }}$ from the value of the initial concentration and working dose of active sludge.

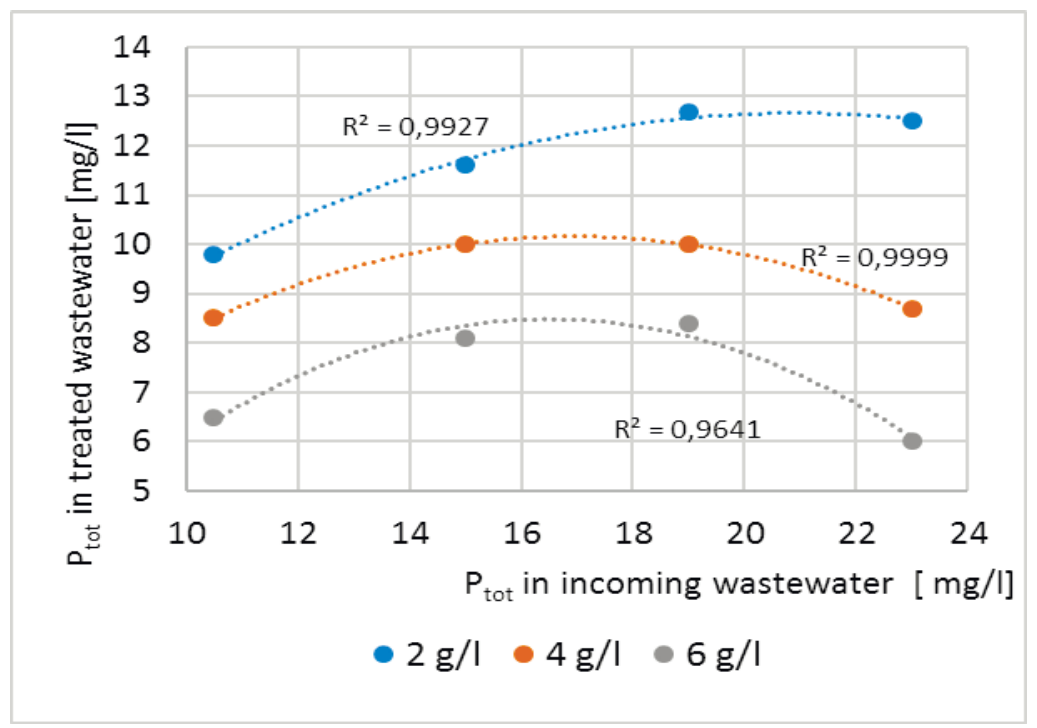

Fig. 3. Effect of the initial content of total phosphorus and operational dose of activated sludge in the aeration tank on the residual concentration of total phosphorus in treated wastewater.

From the data, it follows that with a certain (specific) concentration of $\mathrm{P}_{\text {tot }}$ in the original water, the use of higher active doses of sludge in aeration tank allows to achieve higher level of purified water in the content of residual concentrations of total phosphorus. This is evident in factual research: biological treatment of wastewater with $23 \mathrm{mg} / \mathrm{L}$ of $P_{\text {tot }}$ and dose of $2 \mathrm{~g} / \mathrm{L}$ provided the purification equal to $12 \mathrm{mg} / \mathrm{L}$, while when the dose of sludge was increased up to $4 \mathrm{~g} / \mathrm{L}$ or $6 \mathrm{~g} / \mathrm{L}$, residual concentrations of $\mathrm{P}_{\text {tot }}$ were reduced to 8 $\mathrm{mg} / \mathrm{L}$ and $6 \mathrm{mg} / \mathrm{L}$ accordingly.

However, if aeration tank is operated with a constant dose of sludge, and the fluctuations of phosphorus concentrations are high (which is typical for urban wastewater), the concentration of $\mathrm{P}_{\text {tot }}$ in treated water changes slightly. Analysis of the obtained data confirms the existence of sorbation mechanism for the removal of total phosphorus.

The hydrolysis of complex forms of phosphorus in aeration tank leads to an increase in phosphate content. Depending on the ratios of different forms of phosphorus in the wastewater coming to the treatment and accepted technological parameters of the biological process in the purified water not only a reduction of phosphates may be observed because 
of their assimilation, but even their growth. The ratio of $\mathrm{P}_{\text {tot }}: \mathrm{PO}_{4}$ in biological cleaning is $0.6-0.8$.

The results show that it is not possible to reach the standards at any baseline of phosphorus content.

The method to ensure the deep removal of phosphorus is biological method with anaerobic, anoxic, and aerobic processes. In this case, the deep removal of phosphorus is due to the increased inclusion of phosphates in the cells of active sludge, and additional withdrawal of phosphates with excess of sludge. Another method of deep removal of phosphorus is chemical method using a reagent. Main removal of phosphorus takes place due to the formation of insoluble compounds of phosphates with metal ions. Formed insoluble flakes are involved in activated sludge and are removed from the system with excess sludge. At the same time, in order to remove deeply the total phosphorus from wastewater it is necessary to ensure a deep removal of suspended substances.

\section{Conclusions}

Biological cleaning at higher doses of sludge is accompanied by a rise in the efficiency of removal of the $\mathrm{P}_{\text {tot }}$. Enlarged eliminations of total phosphorus are achieved through sorption processes. Variation of active dose of sludge has a slight effect on the quality of purified water from phosphate. Remaining content of phosphate mainly depends on the original content of the total phosphorus and the ratio of different forms of phosphorus.

\section{References}

1. M. Zaman, M. Kim, G. Nakhla, A. Singh, F. Yang, J. of Env. Sci., 86, 164-174 (2019)

2. D. R. de Graaff, M. C. M. van Loosdrecht, M. Pronk, Water Research, 172, 115531 (2020)

3. G. Bertanza, L. Menoni, G. U. Capoferri, R. Pedrazzani, J. of Env. Management, 254, 109803 (2020)

4. N. Zaletova, Y. Voronov, N. Makisha, Int. J. of Appl. Eng. Research, 10(21), 4245442455 (2015)

5. N. Rey-Martínez, M. Badia-Fabregat, A. Guisasola, J. A. Baeza, Sci. of The Total Env., 657, 1398-1408 (2019)

6. C. Chan, A. Guisasola, J. A. Baeza, Water Research, 118, 217-226 (2017)

7. Y. Zhu, X. Tu, X.-S. Chai, Q. Wei, L. Guo, Bioresource Technology, 251, 7-12 (2018)

8. N. Zaletova, S. Zaletov, I. Bulychev, MATEC Web of Conf., 178, 09021 (2018)

9. R. Bashar, K. Gungor, K. G. Karthikeyan, P. Barak, Chemosphere, 197, 280-290 (2018)

10. B. A. Figdore, H. D. Stensel, M.-K. H. Winkler, Water Research, 135, 241-250 (2018) 